\title{
Del saber sabio al saber dramatizado. Nuevos fundamentos para la aplicación permanente del teatro en el aula
}

\author{
From wise knowledge to dramatized knowledge.
}

New foundations for the permanent application of theater in the classroom

\author{
Luis Fernando Lara Coronado
}

Universidad Academia de Humanismo Cristiano

\begin{abstract}
Resumen
Este ensayo da a conocer un nuevo enfoque del fenómeno teatral que supere la mirada tradicional del teatro en la escuela como teatro-espectáculo, limitado a objetivos lúdico-representativos de índole temporal, para posibilitar su práctica permanente en el aula como activador del desarrollo del pensamiento. Para ello se analiza el origen de la tensión entre teatro-espectáculo y aula-espectáculo, develando el enfoque historicista que subyace en el uso tradicional del teatro en la escuela, y sus consecuencias en la fallida implementación del teatro en el currículum como activador del pensamiento creativo. Así se evidencia la debilidad e inconsistencia del fundamento historicista para otorgar al teatro su status de saber sabio escolarizable, y se plantea una redefinición del teatro como saber, la cual permita instalarlo de manera permanente en el aula.
\end{abstract}

Palabras clave: teatro, historicismo, transposición didáctica, constructivismo.

\begin{abstract}
This essay reveals a new approach to the theatrical phenomenon that surpasses the traditional view of theater in school as theaterspectacle, limited to playful-performing objectives of a temporary nature, to enable its practice permanent in the classroom as an activator of the development of thinking. For this, the origin of the tension between theaterspectacle and classroom-spectacle is analyzed, revealing the historicist approach that underlies the traditional use of theater in school and its consequences in the failed implementation of theater in the curriculum as an activator of creative thinking. This demonstrates the weakness and inconsistency of the historicist foundation to grant the theater its status of scientific knowledge and a redefinition of theater as knowledge is proposed, which allows it to be installed permanently in the classroom.
\end{abstract}

Keywords: theatre, historicism, didactic transposition, constructivism

Recibido: 3-10-17. Aceptado: 13-12-17

Luis Fernando Lara Coronado es Magíster en Educación, Mención Multiculturalidad, y trabaja como profesor.

Contacto: L. F. Lara, C/ Colón 1265, comuna de Independencia, Santiago.

profesorfernandolara@gmail.com

Cómo citar: Lara, L. F. (2018). Del saber sabio al saber dramatizado. Nuevos fundamentos para la aplicación permanente del teatro en el aula. Revista Stultifera, 1 (1), 60-82. ISSN 0719-983X

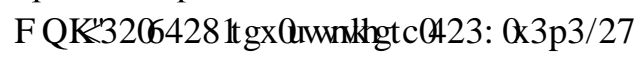




\section{DEL SABER SABIO AL SABER DRAMATIZADO}

\section{Inconsistencias del enfoque historicista para el uso permanente del teatro en la escuela}

El ingreso del teatro dentro del currículum suponía materializar la aspiración de instalarlo como actividad permanente dentro del contexto escolar y superar su uso restringido o excepcional. El objetivo de esta inclusión era activar las clases, promoviendo la creatividad del pensamiento de los estudiantes de manera transversal por medio del juego dramático. Este enlace entre juego y desarrollo de la creatividad dio el respaldo necesario a los objetivos curriculares de corte constructivista definidos por la Reforma Educacional.

Sin embargo, en la práctica pedagógica, el teatro continúa siendo una actividad restringida a iniciativas aisladas y temporales. Hasta el día de hoy se la sigue considerando una actividad subordinada al ámbito artístico-literario, específicamente en el subsector de Lenguaje y Comunicación. Su inclusión en el sector de Educación Artística —inadvertida para la mayoría de los docentes, pese a tener más de una década de antigüedad - no ha mejorado esta percepción, sino al contrario, ha impuesto la perspectiva del teatro-espectáculo y su especificidad literaria, como estimulador natural del pensamiento creativo, pero limitado al ámbito artístico, impidiendo su despliegue transversal. Entonces surge la pregunta obvia: ¿por qué el teatro sigue siendo una actividad restringida y no permanente dentro del aula escolar, a pesar de su inclusión en el currículum como asignatura?

La respuesta está dada por el mismo enfoque historicista que le dio origen. Se asume el teatro como un producto histórico, el cual tuvo una evolución, y llega hasta la escuela rodeado del aura de sus múltiples posibilidades didácticas definidas en su particular proceso creativo, que involucra todos los ámbitos de la expresión y cuyo punto cúlmine se alcanza en la representación. Pese a los argumentos que señalan la importancia de los aprendizajes alcanzados en el proceso creativo dramático, por sobre la representación final, no se puede negar la virtualidad teatral. El alumno asume la representación como un fin, porque culturalmente ha sido formado desde ese enfoque. Lo mismo puede decirse del juego. El juego dramático supone objetivos y resultados definidos previamente por el docente, de los cuales el niño no es completamente consciente; pero sí lo es del sentido lúdico del rompimiento de la rutina escolar. En otras palabras, el teatro-espectáculo se convierte en un fin en sí mismo y no en un medio al servicio del desarrollo integral del estudiante. 


\section{LUIS FERNANDO LARA CORONADO}

Por otra parte, el encasillamiento de la actividad teatral en la representación define su alejamiento del aula, la cual no resiste los singulares requerimientos del espacio teatral, en relación al montaje, escenografía y manejo grupal, propios de la representación, de manera continua; se transforma, así, en una actividad evitada por los docentes, en especial por aquellos que no pertenecen al ámbito de las artes, quienes comprenden su valor artístico, pero no su relación o aporte en otras áreas. Por esta razón, se acepta tan fácilmente su uso restringido y eventual.

En síntesis, la aplicación de un enfoque historicista sobre el fenómeno teatral revela tres inconsistencias fundamentales que niegan al teatro su función activadora de la creatividad del pensamiento, su rol integrador y transversal de acuerdo a los objetivos constructivistas del currículum y sus reales alcances didácticos dentro del aula: (a) incompatibilidad entre el enfoque historicista y el constructivismo en el currículum; (b) incompatibilidad entre el enfoque historicista y el constructivismo en la transmisión didáctica del teatro; (c) ineficacia de la metodología activa en el aula: la tensión entre el concepto de teatro-espectáculo y aula-espectáculo. Estas tres inconsistencias se encuentran estrechamente relacionadas y tienen importantes repercusiones en el ámbito educativo, como veremos a continuación.

\section{Incompatibilidad entre el enfoque historicista y el constructivismo en el}

\section{currículum.}

Como ya se dijo, la escuela recibe al teatro como un producto histórico, el resultado último de un proceso evolutivo determinado por períodos de carácter secuencial. La concepción del saber como producto histórico responde a una mirada historicista de la realidad en su sentido más amplio.

El origen de esta mirada se articula en el esfuerzo por convertir la Historia en una disciplina científica autónoma. Esta perspectiva de la Historia dio forma en el siglo XIX a un nuevo paradigma del conocimiento que haría surgir el movimiento filosófico conocido como historicismo. De acuerdo a la definición de Benedetto Croce, "historicismo, en el uso científico de la palabra, es la afirmación de que la vida y la realidad son Historia y nada más que Historia” (Croce, 1942, p. 71). 


\section{DEL SABER SABIO AL SABER DRAMATIZADO}

El historicismo pretendía explicar la realidad desde un punto de vista distinto de las ciencias naturales, pero asimilando alguno de sus principios en relación a la existencia de leyes históricas a la manera de las leyes naturales; pero con la diferencia de que las leyes históricas tendrían un carácter evolutivo, y no repetitivo, como las leyes biológicas. Estas leyes históricas se definían en etapas muy similares a las fases del desarrollo biológico de los organismos vivientes.

De esta manera, Johann Gottfried Herder, uno de los pioneros de este movimiento, articula las etapas de la historia en términos de infancia (Oriente, historia de los patriarcas), adolescencia (cultura egipcia y fenicia), juventud (Grecia, que representa la edad de las artes, de la armonía, la curiosidad por saber, el patriotismo y la conquista de la libertad), virilidad (que corresponde a Roma: austeridad, dominio y poder), madurez (irrupción de los bárbaros, Edad Media), y senectud (decadencia). La conclusión final de Herder "es que tanto la evolución de la cultura como de la naturaleza misma, sobre la cual se apoya la primera, se ha producido conforme a un fin último: la formación de la humanidad" (Herder, 2002, p. 11).

Tras esta concepción de la Historia subyace la idea de progreso de raíz evolucionista, la cual, pese a la crítica posterior al Historicismo, ha permanecido hasta hoy, tal y como se evidencia en los textos de estudio, que insisten en presentar el conocimiento dentro de una cadena evolutiva progresista, cuyo producto final es el conjunto de saberes seleccionados por el currículum. Esta percepción tendría su origen en un enfoque historicista del fenómeno teatral, en el cual la didáctica teatral asociada a la escuela correspondería a la última y más reciente etapa de un proceso histórico compuesto de tres momentos: el origen del teatro como espectáculo, la evolución del teatro hacia el género dramático y la didáctica teatral como referente cultural. Estos tres elementos dan forma a una concepción evolutiva tripartita del fenómeno teatral, y articulan la génesis histórica del uso tradicional del teatro en la escuela.

La base de este enfoque historicista de la evolución teatral se estructura en torno a tres conceptos claramente diferenciados: teatro, drama y didáctica, los cuales -de acuerdo al Diccionario Etimológico de W.W. Skeat (1963) — apuntarían comúnmente a los siguientes significados: teatro (del griego theatron: lugar para ver, observar), drama (del griego drama y este del verbo drao: hacer, actuar), didáctica (del griego didaskalia: enseñanza) 


\section{LUIS FERNANDO LARA CORONADO}

Por lo tanto, la concepción tripartita se daría en la evolución del teatro como espectáculo, para verla luego en su transformación en un hacer artístico-literario, y finalmente, en su consagración académica en la didáctica teatral. Solo cuando el teatro se hace obra literaria y, por lo tanto, objeto cultural, alcanza un status académico que lo puede conectar con el ámbito educativo escolar. Una vez diferenciados estos tres aspectos desde el enfoque historicista, surge la conexión con la didáctica escolar, que se apropia de este referente cultural y lo sistematiza. En consecuencia, desde este punto de vista, podemos explicar la evolución del fenómeno teatral y su conexión con la implementación del teatro escolar de acuerdo a las siguientes etapas: (a) el teatro como espectáculo; (b) el teatro como género literario; (c) el teatro como referente didáctico.

Desde este punto de vista, si nos atenemos a una visión evolutiva tripartita del fenómeno teatral damos como asumida la evolución progresiva del teatro-espectáculo hasta su conformación en saber, hecho que se consagra con su incorporación al currículum y la posibilidad de adquirir un estatus permanente dentro de la escuela.

Sin embargo, aquí surge la primera contradicción, pues no parece compatible una perspectiva que asume los saberes como productos históricos, con una mirada constructivista que define el saber como un proceso de construcción continuo, mediante el cual se renueva el conocimiento. El término constructivismo "contiene referencias en cuanto a que los seres humanos, tanto individual como grupalmente, construyen ideas en relación a cómo funciona el mundo. Estas ideas no son estáticas, sino que cambian con el tiempo y la experiencia" (Alarcón, 2006, p. 13). En consecuencia, el teatro no puede ser concebido como un producto histórico, sino que debiera ser asumido como un fenómeno en constante movimiento y construcción, para poder ser conectado con los lineamientos constructivistas del currículum y abrir sus posibilidades más allá de los objetivos lúdico-representacionales del teatroespectáculo.

Desde esta perspectiva, no es de extrañar que la inclusión curricular del teatro se base fundamentalmente en la forma y el contenido de los manuales teatrales. De hecho, dentro de las orientaciones didácticas del Programa Ministerial, se recomienda insistentemente el apoyo complementario del manual de Verónica García-Huidobro, Pedagogía teatral: 


\section{DEL SABER SABIO AL SABER DRAMATIZADO}

metodología activa en el aula, incluido íntegramente en el Anexo 2 del mismo Programa (MINEDUC, 2001, p.67). El formato del manual responde a una concepción estática del conocimiento, como producto histórico incuestionable. Esto explicaría el sorprendente parecido entre los diversos manuales que encasillan la actividad teatral en el ámbito de la representación, pese a las constantes referencias que consolidan al juego dramático como la base argumentativa que relaciona el saber teatral con el constructivismo.

En efecto, uno de los temas reiterados en casi todos los manuales teatrales proconstructivistas es la diferenciación entre los objetivos del teatro propiamente tal y el juego dramático, concibiendo este último como un puente del desarrollo de la creatividad. De esta manera, el teatro tendría como objetivo principal la representación, mientras que el juego dramático pretendería el libre despliegue de la creatividad.

Precisamente fue esta visión del juego uno de los pilares teóricos que posibilitaron la introducción del teatro en el currículum. Pero, en la práctica, esta diferenciación carece de sentido, pues la mayoría de los manuales, intentando apartarse del mero objetivo representacional del teatro-espectáculo y otorgarle al juego un rol estimulador de la creatividad del pensamiento, lo definen desde un punto de vista evolutivo secuencial, en forma paralela a las etapas del desarrollo del niño y el adolescente. De este modo, sitúan la actividad lúdica en las primeras etapas de su evolución hacia la dramatización y la representación de la obra teatral. Este tipo de clasificación jerarquiza inevitablemente la actividad teatral, quedando el juego solo como una fase primaria en el camino hacia el teatroespectáculo, tal como podemos advertir en el Manual de Pedagogía Teatral de Verónica García-Huidobro:

\section{ETAPAS DE DESARROLLO DEL JUEGO}

ETAPA I ( 0 a 5 años)

Primera subetapa (de cero a tres años): se caracteriza por el juego personal, el cual se reconoce porque el niño está completamente absorto en lo que está haciendo. Se trata de una vigorosa forma de concentración infantil que sustenta sus primeras manifestaciones expresivas. Es una actitud creativa, individual, solitaria y ensimismada que excluye la necesidad de público (...)

Segunda subetapa (de tres a cinco años): se caracteriza por el juego proyectado, el cual se reconoce porque el niño experimenta la necesidad emocional de comunicarse y compartir con otro para jugar $(\ldots)$ 


\section{LUIS FERNANDO LARA CORONADO}

ETAPA II (5 a 9 años)

Primera subetapa de cinco a siete años): se caracteriza por el juego dirigido, el cual se reconoce porque el niño acepta la interacción de un tercero que orienta el sentido del juego, con el fin de desarrollar capacidades y destrezas específicas (...)

Segunda subetapas (de siete a nueve años): se caracteriza por el juego dramático, el cual se define como la práctica colectiva que reúne a un grupo que improvisa a partir de un tema $(\ldots)$

ETAPA III (9 a 15 años)

Primera subetapa (de nueve a doce años): se caracteriza por el juego dramático, que apunta, en forma cada vez más evidente, a la toma de conciencia de los mecanismos y conceptos fundamentales del teatro, tales como tema o argumento, personaje, situación, diálogo, conflicto y desenlace (...)

Segunda subetapa (de doce a quince años): se caracteriza por la improvisación, definida como una técnica de actuación donde el actor representa algo imprevisto, no preparado de antemano e inventado al calor de una acción (...)

ETAPA IV (15 a 25 años)

Primera subetapa (de los quince a los dieciocho años): se caracteriza por la dramatización, definida como la interpretación escénica de un texto, utilizando escenario y actores para instalar la situación (...)

Segunda subetapa (de los dieciocho a los veinticinco años): se caracteriza porque el joven adulto quiere hacer teatro, definido como el arte de poner en escena un texto utilizando escenario, director, actores, escenografía, vestuario, utilería, maquillaje, música y efectos especiales para instalar el discurso escénico. (García-Huidobro, 2000, pp. 20-23)

Una versión resumida de este esquema se incluye en el Anexo 2 del Programa de Teatro (MINEDUC, 2001, p.68), confirmándose los criterios historicistas que subyacen en el currículum y que impiden que el juego se conecte con los objetivos del constructivismo, ya que se encasilla al teatro como espectáculo cuyo fin es la representación.

Este mismo determinismo historicista invade el desarrollo de las unidades curriculares del Programa de Teatro, pues se asume el juego como un ejercicio de preparación previa y de carácter complementario, dentro del proceso dramático que concluirá en la representación. Es más, se le asigna a la representación una función unificadora de todos los objetivos del proceso dramático, incluyendo el aspecto creativo. De este modo, el juego pierde su rol distintivo respecto del teatro, el cual lo situaba en el terreno de autoconstrucción del conocimiento, tal como se observa en los objetivos de la representación dramática en el Programa de Estudio: 


\section{DEL SABER SABIO AL SABER DRAMATIZADO}

La representación integra todos los contenidos de la expresión dramática: el actor o la actriz (rol) con su capacidad corporal, vocal y emocional puesta al servicio de la construcción e interpretación de un personaje; el espacio escénico (entorno) con los aportes creativos y expresivos de la dirección, escenografía, iluminación, música, utilería, el vestuario y maquillaje, entre otros, que contribuyen a la construcción de la ficción; y el texto teatral (estructura dramática) con el valor de la dimensión literaria de la dramaturgia. La representación es la responsable de integrar estos tres grandes aspectos (rol, entorno y estructura dramática) para generar como resultado lo que llamamos el arte del teatro.

La representación en el contexto escolar permite:

* sintetizar las posibilidades de autoexploración y construcción del yo.

* fomentar el espíritu de equipo y el respeto a la diversidad.

* registrar la información del mundo circundante real e imaginario.

* experimentar dinámicas de conocimiento y acción comunicativa.

* favorecer la formación del juicio crítico.

* disfrutar de la actitud creativa y expresiva.

Los juegos y ejercicios correspondientes generalmente implican:

*Conocer las reglas de la representación (juegos de rol, juegos dramáticos, improvisaciones, dramatizaciones).

* Integrar los aspectos de la dramatización (interpretación, entorno y estructura dramática) en las representaciones.

*Ejercer el dominio creativo e interpretativo de la expresión dramática. (MINEDUC, 2001, p.31-32).

En síntesis, la evidente incompatibilidad entre el enfoque historicista del saber y el constructivismo impiden que el teatro salga de los límites del teatro-espectáculo y su objetivo lúdico-representacional. En este sentido, las dificultades que encierra el proceso de creación dramática y su montaje siguen alejando al teatro de una inclusión permanente en la escuela, y determinan la continuidad de su uso a nivel de talleres o iniciativas aisladas, no justificándose su incorporación en el currículum, como estimulador de la creatividad del pensamiento dentro de la perspectiva constructivista.

\section{Incompatibilidad entre el enfoque historicista y el constructivismo en la} transmisión didáctica del teatro.

Otra de las consecuencias del enfoque historicista está relacionada con la forma en la cual se transmite el conocimiento. Al ser incorporado dentro del currículum, el teatro es aceptado con la categoría de saber sabio o producto histórico, lo cual faculta su conversión de saber sabio a saber enseñado. El docente solo debe transformar este saber consagrado por 


\section{LUIS FERNANDO LARA CORONADO}

la historia y hacerlo accesible al estudiante. Este proceso de transformación de un saber sabio a un saber enseñado constituye la base funcional de la didáctica. Yves Chevallard explica este proceso de la siguiente manera:

un contenido del saber sabio que haya sido designado como saber a enseñar sufre a partir de entonces un conjunto de transformaciones adaptativas que van a hacerlo apto para tomar lugar entre los objetos de enseñanza. El "trabajo" que un objeto de saber a enseñar hace para transformarlo en un objeto de enseñanza se llama transposición didáctica”. (Gómez, 2005, p. 87)

Según Michel Verret, a quien se atribuye la paternidad del concepto de transposición didáctica, este proceso privilegiaría tres aspectos fundamentales: el logro, la continuidad y la síntesis:

El logro, porque en el saber transmitido al alumno (o más precisamente en el saber que se da para transmitir), se ha operado una clasificación: las investigaciones "no exitosas" no serán presentadas. Los titubeos, los tanteos y los fracasos de la investigación serán de esta forma ahorrados o evitados a los alumnos.

La continuidad, porque la transmisión didáctica no tendrá en cuenta las interrupciones y la huella del tiempo sobre las investigaciones: ella presupone "la transmisión histórica exitosa de las investigaciones exitosas".

La síntesis, porque en la transmisión de los saberes a los alumnos, los momentos fuertes de la investigación serán detenidos o reservados para "hacer la economía del detalle". (Gómez, 2005, p.85)

Esta concepción del proceso de transposición didáctica pone en evidencia las graves consecuencias que supone la aplicación de un enfoque historicista sobre el conocimiento. En primer lugar, en relación al logro, se confirma que el saber es presentado como el resultado o producto final de un proceso. El maestro transmite un saber como producto histórico, cuyo éxito lo exime de cualquier cuestionamiento, impidiendo el análisis crítico y la reflexión del alumno, objetivo vital del enfoque constructivista. En segundo lugar, el dejar de lado la duda y los titubeos investigativos significa negar al alumno la posibilidad de construir el conocimiento a partir de sus propias experiencias, y asumir el temor a la incertidumbre y el error como elementos esenciales en este proceso. De esta forma, solo se transforma en un consumidor de contenidos exitosos, productos de una evolución histórica progresista, definida en la continuidad. Finalmente, la síntesis que supone la selección de elementos relevantes para "hacer economía del detalle", la realiza el docente, el cual en realidad está 


\section{DEL SABER SABIO AL SABER DRAMATIZADO}

"economizando" procesos de construcción del pensamiento que debieran realizar sus propios alumnos.

Esto explicaría el fallido intento por transformar el juego dramático en una herramienta para el desarrollo de la creatividad del pensamiento. El juego dramático fue insertado como una etapa primaria dentro de un saber sabio, históricamente incuestionable y sacralizado por la cultura, y fue funcionalmente anulado. El juego se define por el tanteo experimental, la prueba y el error. El juego permite perder el temor a equivocarse, a salirse de los esquemas, a reinventar las reglas. Por esta razón, no puede ser inscrito en un esquema hermético que lo transforme en parte de un saber erudito.

Por lo tanto, el proceso de transposición didáctica del teatro no permite dar libertad ni espacio a la creatividad como base del proceso de construcción del conocimiento. El teatroespectáculo entra al proceso de transposición didáctica y sale de la misma forma en la que entró. ¿Cómo se explica esta situación paradojal? ¿Significa acaso que el teatro no constituye un saber escolarizable o susceptible de transposición didáctica?

El problema reside en que el proceso de transposición de un saber sabio a un saber enseñado no se puede aplicar en el caso del teatro, porque este saber no solo nace como práctica social, sino que no puede separarse de ella. Es en la práctica dramática donde se conforma el saber teatral; por consiguiente, seleccionar contenidos y metodologías que aterricen el arte teatral en la escuela no tiene sentido, porque la actividad teatral, ya sea en sus formas más simples o más complejas, siempre será encaminada hacia la representación escénica. En otras palabras, si aplicamos en el teatro la perspectiva didáctica de la transposición como en cualquier otro saber, se seguirá haciendo teatro-espectáculo como hasta ahora, es decir, no se justificaría su inclusión dentro del currículum como estimulador de la creatividad. Lo anterior se reafirma en la evidente falta de novedad de los contenidos que aparecen en el Programa de Estudio del Plan Diferenciado de Teatro o Danza, pese a todos los esfuerzos renovadores que prometía la inclusión del teatro en el currículum.

Para Michel Verret no todos los saberes son escolarizables. Deben cumplir ciertos requisitos para poder ser considerados productos de transposición didáctica: "la desincretización, la despersonalización, la programabilidad de la adquisición del saber y la publicidad y control social de los aprendizajes" (Gómez, 2005, p. 89). 


\section{LUIS FERNANDO LARA CORONADO}

La desincretización es la primera etapa en la conformación de un saber. Esta consiste en la delimitación de los saberes, la cual se expresa en la articulación de un discurso autónomo para cada saber. Estos campos de saberes delimitados dan origen a las prácticas de enseñanzas especializadas. Esto significa su descontextualización de la red de problematizaciones que le dieron origen y sentido.

Podemos advertir que, en el caso del teatro, esta etapa no ocurre, pues en la actividad dramática se integran un conjunto de saberes más allá de los meramente artísticos. Si bien la actividad dramática es considerada "la síntesis de todas las artes", su estructura dialéctica le permite integrar las más variadas temáticas que abarcan el espectro humanista, científico y filosófico. Un ejemplo claro lo constituyen los diálogos de Platón, los cuales confirieron un carácter dramático a la reflexión filosófica, y determinaron el carácter trágico de la figura de Sócrates a través del tiempo.

La despersonalización consiste en la separación paulatina del saber y la persona. Todo saber sabio en el momento de su nacimiento se ata a su productor. Este proceso culmina en el momento de la enseñanza, de modo que el saber se torna creíble porque no le pertenece a quien lo emite, es un saber consagrado por la historia.

El teatro no admite la despersonalización, el teatro vive del personaje, de la representación de un conflicto reconocible en personas. La estructura dialógica responde a la necesidad de dar vida y pensamiento a los personajes, y revivir en los vaivenes del conflicto representado, el origen de un problema, su contextualización y consecuencias. Un claro ejemplo de lo anterior, es la trascendencia de personajes como Hamlet, o Romeo y Julieta, los cuales se atan inevitablemente a la figura de Shakespeare en la memoria colectiva.

La programabilidad de la adquisición del saber se refiere a la exigencia de una programación o secuencia en la presentación del saber, lo cual permita su asimilación y aprendizaje. Debe definir una norma de progresión del conocimiento, con un comienzo, un intermedio y un fin.

El teatro no se encasilla en una secuencia ni en un libreto; asume desde su origen el valor de la improvisación, la espontaneidad y el juego. En este sentido, el teatro recrea la 


\section{DEL SABER SABIO AL SABER DRAMATIZADO}

capacidad del hombre de adaptarse a cualquier circunstancia. La obra dramática más estructurada es representada en cada ocasión de manera diferente, inclusive con distintos actores, quienes deben estar preparados ante cualquier eventualidad, incluyendo cambios en el guión, cuando éste no parece funcionar ante el público. Es el espectador quien decidirá finalmente si la secuencia dramática ideada por el autor es la correcta y atrapa su atención.

La publicidad y control social de los aprendizajes apunta a la textualización del saber; cuando el saber se convierte en texto se hace público, y esta publicidad permite divulgar cierta concepción del saber e imponer su uso curricular, consiguiendo el control social de los aprendizajes.

En el caso del teatro, es la virtualidad teatral lo que le da sentido a la actividad dramática, no su valor textual. La obra escrita no es más que un intento de transcribir artísticamente la representación viva imaginada por el autor. Es una guía para darle vida a un conflicto, una sugerencia interpretativa, sometida al parecer de quien quiera representarla a través del tiempo. No cabe el control social; la obra se justifica por sí misma ante el público, se la acepta o rechaza. Lo mismo cabe para el juego o la improvisación; son actividades que se justifican en la práctica, no en el manual, y son las personas quienes juzgan su valor, utilidad y trascendencia; no se pueden imponer a la fuerza.

En definitiva, el teatro como espectáculo no constituye un saber escolarizable o susceptible de transposición didáctica; el teatro nace como espectáculo y no puede asumir otra forma dentro de esta perspectiva didáctica. En otras palabras, ni su inclusión curricular ni su transmisión didáctica permiten otorgar al teatro un lugar permanente en la escuela, como estimulador de la creatividad del pensamiento.

\section{Ineficacia de la metodología activa en el aula: la tensión entre el concepto de teatro-espectáculo y aula-espectáculo.}

Si el teatro constituye un saber no susceptible de transposición didáctica, quiere decir que no constituye un saber escolarizable, o sea, queda afuera del aula escolar. El teatro es espectáculo y no puede asumir otra forma desde la perspectiva historicista, y este espectáculo debe darse fuera del aula, en un espacio concreto determinado histórica y culturalmente para ese fin. De este modo, el aula pierde su rol protagónico como espacio generador de procesos 


\section{LUIS FERNANDO LARA CORONADO}

de aprendizaje y desarrollo del pensamiento. El teatro-espectáculo oculta tras la parafernalia representativa el espectáculo de construcción del saber generado en el aula, que determina el concepto de aula-espectáculo. De esta forma, los alumnos disocian lo enseñado en clases con el espectáculo representado, al cual ven como el producto exitoso, históricamente consagrado, y el trabajo en el aula solo como la fase preparatoria y experimental que no debe ser considerada en pro del resultado final. Esto origina la tensión entre teatro-espectáculo y aula-espectáculo.

Además, la imposibilidad del teatro de transformarse didácticamente impide su despliegue transversal en el aula, ya que siempre será concebido como teatro-espectáculo y representación. Esto explicaría la resistencia al teatro por parte de docentes que no pertenecen al área artística. No conciben la aplicación del teatro de manera transversal, porque es prácticamente imposible transportarlo a otras áreas desde la perspectiva de la transposición didáctica, si no es en la forma de teatro-espectáculo. Si bien el teatro activa las clases, rompiendo la rutina escolar, a la larga se transforma en una actividad extenuante para el maestro, lo cual impide su uso continuo. Por esta razón, muchos docentes abandonan la actividad teatral y prefieren buscar alternativas más simples y menos exigentes que el teatro para darle más dinamismo a las clases.

La imposibilidad de transposición didáctica y despliegue transversal del teatro quedan confirmadas en la falta de concordancia entre las promesas ofrecidas con la inclusión del teatro en el currículum y la realidad de su incorporación en el aula escolar.

Previamente a la incorporación del teatro al currículum, Verónica García Huidobro, en su Manual de Pedagogía Teatral, ya hacía alarde de las posibilidades del drama de convertirse en un eje articulador de la transversalidad didáctica. Allí señala que, además de constituirse como ramo o curso de expresión dramática, la pedagogía teatral se constituye "como herramienta pedagógica para otros cursos del currículo escolar (castellano, matemáticas, ciencias sociales, naturales, idiomas, entre otros)" (García-Huidobro, 2000, p. 17).

Esta perspectiva, provocó un gran entusiasmo en torno a las posibilidades del teatro como activador de la creatividad en el aula a través del juego: "El docente introduce la 


\section{DEL SABER SABIO AL SABER DRAMATIZADO}

metodología en el ramo donde considere necesario y aportador el juego dramático para apoyar la materia, buscando activar y volver más ameno el proceso de aprendizaje de sus educandos" (García-Huidobro, 2000, p. 17).

Esto abría las posibilidades de insertar el teatro en el aula de manera permanente a través del juego dramático y, así, superar la tensión entre teatro-espectáculo y aulaespectáculo. El teatro, por fin, tenía la posibilidad de salir de su encasillamiento en la representación pública del teatro-espectáculo, lo cual suponía cumplir una serie de requerimientos dentro de un contexto limitado en recursos y en el cual los profesores no contaban con una preparación previa en este ámbito.

Sin embargo, en el año 2001, cuando el teatro pasa a formar parte del currículum, solo se valida su transversalidad en el ámbito artístico, insertándolo directamente en el sector de Educación Artística, el más cercano a su objetivo de representación escénica; se subordina, así, el juego a este objetivo, como podemos apreciar en la presentación del Programa de Estudios:

La representación teatral posee el don de hacer interactuar diferentes códigos artísticos, respetando sus propios lenguajes, con el objetivo de producir un discurso propio con múltiples portales de acceso de orden sensorial, afectivo, intelectual y valórico. Desde el origen podemos deducir el enorme potencial integrador que posee el arte del teatro como mediador de la alfabetización artística, promoviendo procesos y resultados interactivos de elaboración escénica y síntesis crítica. (MINEDUC, 2001, p. 7)

En consecuencia, el teatro como resultado de una evolución histórica solo puede ser concebido como teatro-espectáculo, y el juego, como una fase primaria o preparatoria de la representación. El aula será concebida, así, como el lugar del ensayo o preparación previa para la representación y no como el lugar permanente del desarrollo de la creatividad del pensamiento. Esta tensión entre teatro-espectáculo y aula-espectáculo ha impedido el diálogo transversal del drama, porque es en el aula donde se construyen las experiencias integradoras y no en la representación pública, lo cual anula los esfuerzos por hacer conscientes a los alumnos del valor del proceso creativo por sobre la representación pública.

En conclusión, la determinación historicista sobre el currículum y la transmisión didáctica impiden que el teatro sea instalado como una actividad permanente en el aula, con 


\section{LUIS FERNANDO LARA CORONADO}

el propósito de desarrollar la creatividad del pensamiento de los educandos de acuerdo a los postulados constructivistas, que fue el objetivo principal para incorporarlo en el currículum.

Además, la imposibilidad de transposición didáctica del teatro lo convierte en saber no escolarizable y, por ende, ajeno al ámbito del aula escolar. Solo si un saber puede ser transpuesto o adaptado en la planificación en una forma distinta a su forma erudita, puede ser integrado transversalmente en las diferentes asignaturas dentro del aula. Esto perpetúa la tensión entre teatro-espectáculo y aula-espectáculo. Por lo tanto, el teatro se mantiene como una actividad restringida, sin que su incorporación al currículum haya cambiado esta situación.

\section{Del saber sabio al saber dramatizado: la construcción del saber teatral}

Para replantear el uso del teatro en la escuela y darle un lugar permanente en el aula para el desarrollo de la creatividad del pensamiento, es imprescindible salir del enfoque historicista y darle una nueva mirada al teatro, como saber, desde una perspectiva constructivista. Para ello, lo primero que debemos hacer es redefinir su estatus de saber e iniciar una búsqueda indagatoria que responda a la siguiente interrogante: si el teatro no es un saber escolarizable, ¿qué clase de saber es?

Según Chevallard, todo saber es una respuesta a una pregunta originada en la interacción humana, en la práctica social. Para que se pueda hablar de sistema didáctico, no solamente es necesario que las preguntas tengan una respuesta, sino que, además, estas respuestas hayan sido aceptadas en la sociedad de la época. Si este saber logra responder de manera adecuada, se textualiza, es decir, se convierte en obra. Es la selección de estas obras lo que conforma el conjunto de saberes del currículum escolar: "yo llamo obra, toda producción humana cuyo objeto es aportar una respuesta a una o varias preguntas teóricas o prácticas, que son las razones de ser de la obra” (Gómez, 2005, pp. 90-91).

Sin embargo, desde un enfoque constructivista del conocimiento, concebir el saber como una respuesta consagrada por la historia cierra la posibilidad de nuevas miradas sobre los contenidos culturales e impide la generación de nuevas preguntas. El proceso constructivo del pensamiento destaca el rol del individuo en la renovación del conocimiento histórico. La creatividad individual supone la capacidad del individuo para aprovechar los aportes que la 


\section{DEL SABER SABIO AL SABER DRAMATIZADO}

cultura ofrece y para cuestionar sus contenidos. Desde este punto de vista, no es la respuesta a una pregunta lo más relevante, sino la sucesión de preguntas que surgen en la búsqueda. El conocimiento no es una respuesta; es un proceso de búsqueda, de indagación continua. En este sentido, su conversión en obra textualizada o escrita lo transforma en producto histórico transmisible como saber sabio, cerrando el proceso de indagación.

Ya Platón había señalado los peligros de la textualización en el diálogo Fedro a través de las palabras que el rey egipcio Thamus dirige a Theut, inventor de la escritura:

Ofreces a los alumnos la apariencia, no la verdad de la sabiduría; puesto que cuando ellos, gracias a ti, habrán leído tantas cosas sin ninguna enseñanza, se creerán en posesión de muchos conocimientos, a pesar de permanecer fundamentalmente ignorantes y se harán insoportables a los demás, porque poseerán no la sabiduría, sino la presunción de la sabiduría. (Platón, citado en Abbagnano, 1994, p. 48)

Este es el motivo por el cual su maestro Sócrates nunca trasladó a la escritura su pensamiento. Para Sócrates, el escrito podía comunicar una doctrina, no estimular la búsqueda. La pregunta que daba inicio a la búsqueda filosófica se transfiguraba en respuesta por el solo hecho de textualizarse, interrumpiendo el afán indagatorio del pensamiento. Sócrates nunca pretendió comunicar un saber, sino una nueva forma de enfocar el saber, libre de dogmatismos y determinaciones historicistas. Él no buscaba respuestas, sino ayudar a su interlocutor a ser consciente del proceso intelectual que significaba dar a luz el conocimiento, cuestionando las respuestas entregadas por la historia y la cultura.

Sócrates no criticó la escritura en sí, sino la forma de enfocar el conocimiento que suponía su textualización. Dar a luz el conocimiento suponía un trance lingüísticoexperiencial pleno de dramatismo y vida, que la consideración histórica y cultural sobre el texto escrito hacía desaparecer.

La misma convicción contra la textualización que defendía su maestro impulsó a Platón a buscar, entre los discursos escritos, uno que permitiera dar a conocer las ideas de Sócrates sin transformarlas en verdades incuestionables. De acuerdo al testimonio de Diógenes Laercio, Platón era un experimentado autor, el cual "escribió composiciones éticas, líricas y trágicas, que después quemó" (Abbagnano, 1994, p. 63). De hecho, criticó duramente los espectáculos teatrales de su tiempo por considerarlos artes imitativos de la 


\section{LUIS FERNANDO LARA CORONADO}

realidad que exacerbaban deliberadamente las emociones e impedían corregir al hombre de las ilusiones de los sentidos:

La culpa de la poesía trágica es todavía más grave; nos lleva a conmovernos por las desdichas ficticias que se ven en la escena, a reír inmoderadamente de actitudes bufas que todos debemos condenar en la realidad; y así suministra alientos y vigor a la parte peor del hombre. (Abbagnano, 1994, p. 84)

Sin embargo, rescata la textualidad dialéctica teatral, porque, de todos los discursos escritos, el diálogo es el único que reproduce la forma y la eficacia del discurso hablado. Es la más fiel expresión de la búsqueda, como examen incesante de la realidad. El diálogo era el único medio para comunicar a los demás el verdadero drama de la existencia humana, esto es, la búsqueda del conocimiento:

El diálogo reproduce la marcha misma de la investigación que procede lentamente y con fatiga de etapa en etapa; y sobre todo reproduce su carácter de socialidad y de comunidad, por cuya virtud la investigación se asocia y hace solidarios los esfuerzos de los individuos que la cultivan. Así la forma de la actividad literaria de Platón es un acto de fidelidad al silencio literario de Sócrates; uno y otro parten de la misma base: la convicción que la filosofía no consiste en un sistema de doctrinas, antes bien es búsqueda que replantea incesantemente los problemas, para sacar de ellos el significado y la realidad de la vida humana. (Abbagnano, 1994, p. 69)

El saber, como construcción dramática, se articula en el diálogo incesante de preguntas y respuestas, impidiendo que se perciba como una verdad. De este modo, el tanteo experimental, los errores y fracasos propios de la indagación se ofrecen a la vista como parte fundamental de esa construcción y no como elementos que deben ser borrados de la búsqueda.

En consecuencia, Platón, por medio de sus diálogos, pretendió devolver el dramatismo a la construcción del saber, trasladando la escena teatral al espectáculo del saber, y transformando al maestro y sus discípulos en los protagonistas de la escena pedagógica a través del diálogo indagativo, generador de preguntas y respuestas.

Desde este punto de vista, el teatro no constituiría un saber en sí mismo, sino la representación de un saber, o mejor aún, la dramatización de un saber. Un saber sabio o erudito equivale a un saber despojado de todo dramatismo. La dialéctica teatral permitiría 


\section{DEL SABER SABIO AL SABER DRAMATIZADO}

devolver al saber su carácter dramático, reviviendo los fundamentos teóricos, investigativos y experimentales que lo originaron y el cuestionamiento de su estatus de "verdad". De este modo, el maestro hace partícipe al estudiante del proceso de construcción de un saber e incentiva la construcción de nuevos saberes o nuevas preguntas.

Por lo tanto, ya no es relevante el concepto de teatro como el lugar del espectáculo ficticio y la parafernalia, sino como el espacio — cualquiera sea este- en el cual se desarrolle el espectáculo de la construcción de un saber. El drama ya no se limitaría al quehacer en función de la representación escénica, sino que otorgaría el carácter vital a la construcción dialéctica del saber, en la interacción indagativa entre maestros y discípulos que definen la actividad didáctica. De este modo, se articularía una síntesis entre los conceptos de teatro, drama y didáctica, los cuales ya no se perciben como fases o etapas de una evolución tripartita del fenómeno teatral, sino como distintos aspectos de un todo, denominado educación.

Esta percepción no es gratuita; de hecho, la etimología de la palabra didáctica comprueba que el teatro y la educación desde siempre han conformado una unidad. El origen etimológico del vocablo didáctica se remonta a los orígenes del teatro griego en que se usaba la palabra didaskalia para designar el montaje escénico. Este término significaba enseñar la obra al coro encargado de ejecutarla, lo cual implicaba que, en Grecia, cuando un director dirigía una obra, cumplía al mismo tiempo el rol de "maestro que está enseñando la obra" (García-Huidobro, 2000, p. 16).

Más tarde, con el advenimiento de Esquilo se inicia el teatro como tal. Antes de él, el público solamente oía un simple relato declamado por su propio autor, al cual nada aportaban las interrupciones de los coristas. Este gran dramaturgo fue capaz de transformar el relato en acción: "Esquilo, como Tespis, pero en un plano de superior elevación poética transformó el relato en acción con sus maravillosas tragedias; le agregó un personaje y dio dignidad al coro, confiriendo a su intervención una importancia extraordinaria" (Romero, 1961, p. 11).

De acuerdo a esto, el teatro, desde su origen, cumplía una función educativa que tenía que ver con una espectacularización del proceso de construcción dramática, definida por la interacción didáctica entre el maestro-director-autor y el discípulo-actor; durante esa interacción, este último no solo escuchaba relatos para guardarlos en su memoria, sino que 


\section{LUIS FERNANDO LARA CORONADO}

los vivía como experiencia en la acción dramática. Pero lo más relevante es que el teatro como lugar no solo se percibe como el espacio de la representación escénica, sino que se percibe al mismo tiempo como el ámbito donde ocurre el proceso de construcción del aprendizaje teatral.

Sin embargo, al concebirse el teatro como un saber sabio o producto de una evolución histórica, se pierde la conexión original entre el teatro y la didáctica, o mejor dicho, entre la dialéctica teatral y los procesos de construcción del conocimiento generados en la actividad dramática, ya que el proceso de aprendizaje solo se percibe como un momento previo a la representación y no como una unidad.

El colocar la representación como el objetivo principal de la actividad dramática supone invisibilizar cualquier objetivo didáctico o de aprendizaje, en función de provocar la catarsis o identificación con lo representado en el público, liberando la tensión acumulada a través del conflicto dramático. El público solo será capaz de percibir el teatro como un saber sabio, resultado de un proceso invisible para ellos, y el deseo de ganar la audiencia a través de la catarsis dramática provocará el mismo efecto en los protagonistas de la escena teatral, llámense dramaturgos, directores, actores, etcétera.

Por esta razón, al concebir el teatro como la dramatización de un saber, se recupera la conexión entre teatro y didáctica, perfilándose la actividad dramática en sí misma como un símil de los procesos de construcción del pensamiento sin necesidad de poseer un fin representacional ajeno al aula, puesto que la construcción del saber será lo representado; el aula, el escenario de la representación; y maestro y discípulos, los protagonistas de la escena. Esta conexión entre actividad dramática y procesos mentales de construcción del conocimiento se definen en la dialéctica teatral, tal y como se percibe en el argumento platónico. En este sentido, él mismo llegó a afirmar que "el pensamiento no es más que un discurso que el alma hace consigo misma" (Abbagnano, 1994, p. 69). Por lo tanto, la expresión verbal o escrita solo reproduce la forma necesaria de la búsqueda mental: el diálogo.

\section{El teatro como saber dramatizado: apertura para el uso permanente del teatro en el aula}




\section{DEL SABER SABIO AL SABER DRAMATIZADO}

La concepción del teatro como un saber dramatizado en la escena revela una nueva perspectiva de la relación entre teatro y escuela que nos aparta del enfoque historicista y amplía nuestra mirada sobre el fenómeno teatral, sacándolo de su encasillamiento en la representación y anulando la tensión entre teatro-espectáculo y aula-espectáculo. La nueva visión de la actividad dramática se conecta directamente con los procesos mentales de construcción del conocimiento, los cuales se ven representados en la concepción de un aula activadora del cuestionamiento del saber como producto histórico, a través de la actividad dialéctica que surge con la pregunta o la duda ante el conocimiento dado por cierto. Esta visión implica que el maestro no puede estar ajeno a los mecanismos mentales de procesamiento de la información a fin de articular estrategias que devuelvan el sentido dramático a la construcción del saber, superando la noción de saber sabio por el concepto de saber dramatizado.

\section{El montaje de la "escena pedagógica".}

El cuestionamiento del teatro como saber sabio y su reemplazo por el concepto de saber dramatizado implica a su vez el traslado de la escena teatral al ámbito pedagógico, el cual se espectaculariza y transforma el aula en el escenario de la construcción del conocimiento, articulando la "escena pedagógica". En este sentido, la condena del arte imitativo teatral esgrimida por Platón adquiere una enorme relevancia en la distinción entre las características de la escena teatral y las de la escena pedagógica.

Platón criticó el carácter imitativo de la realidad que configuraba la escena teatral, lo cual significaba que el espectador asistía en cada función a la representación ficticia de la construcción de un saber y no a su construcción real. La explicación mítica del amor, los celos, el misterio de la muerte, el destino, etcétera, concebidos como saberes o contenidos culturales, eran representados en la escena teatral, transmitiendo al público una construcción dialéctica del conocimiento, pero de carácter ficticio, como una copia de la realidad, lo que se oponía directamente a la búsqueda del conocimiento defendida por Platón, ya que exigía "el abandono de toda ilusión respecto a la realidad de las sombras que se nos aparecen en el mundo sensible" (Abbagnano, 1994, p. 84). 


\section{LUIS FERNANDO LARA CORONADO}

Por consiguiente, su condena al arte imitativo teatral se manifiesta como una crítica a su carácter artístico ficcional, que anula los efectos develadores de la dialéctica discursiva, e impide devolver la búsqueda del conocimiento al ámbito de lo real. Desde esta perspectiva, el conocimiento dado por cierto saber sabio sería solo una ilusión de los sentidos, una fícción, que "aborta" el principio dialéctico de la duda o incertidumbre. Solo devolviendo el saber al ámbito de lo real, se posibilita la activación del principio mayéutico de la incertidumbre que "da a luz" el conocimiento.

Por lo tanto, es esencial trasladar la construcción del saber desde la escena teatral ficticia a la escena pedagógica real, convirtiendo al director-autor-actor, transmisor de contenidos culturales, en el maestro-autor-actor, provocador de la duda, y al espectador pasivo en el discípulo-actor, problematizador cultural. De este modo, se articula una escena pedagógica diametralmente opuesta a la escena teatral, tal como podemos observar en la tabla 1:

\section{Tabla 1.}

Comparación entre el teatro-espectáculo y el aula-espectáculo.

teatro-espectáculo

Escena teatral: representación ficcional de la construcción del saber como una respuesta cerrada, la ilusión de un saber verdadero y estático (saber sabio).

a) Director-autor-actor: transmisor de contenidos consagrados por la cultura en el ámbito de la ficción artística.

b) Espectador: consumidor pasivo de cultura. aula-espectáculo

Escena pedagógica: construcción del conocimiento en el ámbito de lo real, como una pregunta generadora del diálogo infinito en busca del conocimiento (saber dramatizado).

a) Maestro-autor-actor: provocador de incertidumbre en la praxis pedagógica.

b) Discípulo-actor: problematizador cultural.

De esta manera, maestro y discípulo se convierten en los actores principales de la escena pedagógica, anulando el conductismo transmisor y la pasividad receptora del espectador, propios de la escena teatral, por medio de la construcción activa del conocimiento en el aula. 


\section{DEL SABER SABIO AL SABER DRAMATIZADO}

En resumen, en este replanteamiento para el uso permanente del teatro en el aula que posibilita el tránsito del teatro-espectáculo al aula-espectáculo, se descubre la correspondencia entre la negación de su carácter como saber histórico y la crítica platónica al arte teatral, que trae como consecuencia la revelación de un nuevo enfoque del fenómeno dramático, que lo define ya no como saber sabio, sino como la dramatización de un saber o saber dramatizado sobre un escenario. En otras palabras, el teatro no sería un saber en sí, sino la representación de la construcción de un saber sobre la escena, a través del diálogo. Así se definiría la verdadera función de la actividad dramática en la educación, que sintetizan la didaskalia griega, donde el director-autor-actor asume el rol de maestro que enseña al coro, labor que realiza sobre el mismo escenario en el que se llevará a efecto la representación, a la manera de lo que debería ser una clase magistral en el aula, fundamentando los principios teórico-prácticos para su uso permanente.

\section{Referencias}

Abbagnano, N. (1994). Historia de la Filosofia. Barcelona, España: Hora S. A.

Alarcón, D., Cortés, A., y Rodríguez, V. (2006). Competencias cognitivas, evaluación constructivista y educación inicial. Santiago, Chile: Bravo y Allende Editores.

Croce, B. (1942). La historia como hazaña de la libertad. Ciudad de México, México: Fondo de Cultura Económica.

García-Huidobro, V. (2000). Manual de Pedagogía Teatral. Santiago, Chile: Editorial Los Andes.

Gómez, M. (julio-diciembre 2005). La transposición didáctica: historia de un concepto. Revista latinoamericana de estudios educativos. 1(1). 83-115.

Herder, J. (2002). Antropología e historia. Facultad de Filosofía Universidad Complutense de Madrid. Madrid, España: Editorial Complutense, S. A.

Mineduc. (2001). Planes y Programas Educación Artística. Programa de Estudio Tercer o Cuarto Año Medio. Artes Escénicas Teatro y Danza. Formación Diferenciada Humanístico-Cientifica. Santiago de Chile: Mineduc. 


\section{LUIS FERNANDO LARA CORONADO}

Romero, L. (1961). El arte del actor. Buenos Aires, Argentina: Editorial Hobby.

Skeat, W. (1963). Diccionario Etimológico de Walter. W. Skeat. Oxford, Reino Unido: Clarendon Press. 


\section{REVISTA STVLTIFERA DE HUMANIDADES Y CIENCIAS SOCIALES}

\section{VOLUMEN 1, NÚMERO 1, PRIMER SEMESTRE DEL 2018}

ISSN 0719-983X

\section{Artículos de Humanidades y Ciencias Sociales}

La violencia como espectáculo.

Juan Carlos Pérez Jiménez

El amo castrado.

Elisa Freijo Corbeira

España, una meditación política: Cataluña y Euskadi.

Mikel Aramburu Zudaire

Del saber sabio al saber dramatizado. Nuevos fundamentos para la aplicación permanente del teatro en el aula.

Luis Fernando Lara Coronado

Ontotecnia, ingeniería organizacional y actores emergentes.

Alejandro Ochoa Arias y Juan Antonio González de Requena Farré

\section{Reseñas}

Memoria Visual de Legua Emergencia, vida y oficio de Mario Alarcón.

Pedro Pablo Achondo Moya

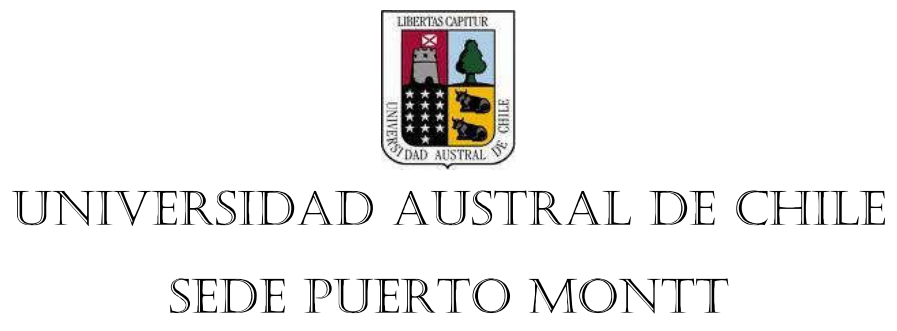

